\title{
Lower Wall Shear Rate of the Common Carotid Artery in Treated Type 2 Diabetes Mellitus with Metabolic Syndrome
}

\author{
E. CHYTILOVÁ, J. MALÍK, Z. KASALOVÁ, R. DOLEŽALOVÁ, T. ŠTULC, R. ČEŠKA
}

Third Department of Internal Medicine, General University Hospital and First School of Medicine, Charles University, Prague, Czech Republic

Received November 8, 2007

Accepted January 14, 2008

On-line April 1, 2008

\begin{abstract}
Summary
Arterial sites with low wall shear stress (WSS) are more prone to the development of atherosclerotic plaques, as was observed in carotid arteries in subjects with atherosclerosis risk factors. Type 2 diabetes mellitus (DM), hypertension, hyperlipidemia and other components of the metabolic syndrome, are associated with high risk for symptomatic cerebrovascular disease. It was shown by others that untreated type 2 DM is associated with lower WSS in common carotid arteries. However, the cardiovascular risk of type 2 DM could be modified by therapy. The aim of our study was to test the hypothesis that treated type 2 DM subjects with metabolic syndrome still have lower WSS in common carotid arteries than healthy controls. We enrolled 26 compensated DM subjects with metabolic syndrome, treated by metformin, statins and ACEI for more than 6 months, and 22 aged-comparable healthy controls. Wall shear rate (WSR) was used as a measure of WSS. A linear 3-11 MHz probe was used to measure blood velocity and internal diameter in the common carotid arteries. We compared observed values of WSR adjusted for age by ANCOVA. Wall shear rate was significantly lower in DM group than in control subjects: peak (systolic) values of wall shear rate were $410 \pm 130 \mathrm{~s}^{-1}$ vs. $487 \pm 111 \mathrm{~s}^{-1}(\mathrm{p}<0.005)$. DM subjects had significantly lower WSR, because of both thinner lumen and slower blood flow velocities. Lower WSR was accompanied by higher IMT $(0.73 \pm 0.12 \mathrm{~mm}$ vs. $0.64 \pm 0.11 \mathrm{~mm}$, $\mathrm{p}<0.001)$. Treated subjects with compensated type 2 DM with metabolic syndrome still have atherogenic hemodynamic profile. These findings might help to understand faster progression of atherosclerosis in diabetic subjects with metabolic syndrome despite up-to-date medication.
\end{abstract}

\section{Key words}

Ultrasonography $\bullet$ Wall shear stress $\bullet$ Wall shear rate $\bullet$ Diabetes mellitus • Carotid artery disease

\begin{abstract}
Corresponding author
E. Chytilova, Third Department of Internal Medicine, General University Hospital, U Nemocnice 1, 12808 Prague 2, Czech Republic. Fax +420 224923852. E-mail: Eva.Chytilova@vfn.cz
\end{abstract}

\section{Introduction}

Atherosclerosis, the leading cause of death in the developed countries, is a consequence of both, the genetic predisposition and the traditional risk factors such as diabetes mellitus (DM) (Mayer-Davis et al. 1998), hypertension (Berenson et al. 1998), hyperlipidemia (Waters et al. 1995), cigarette smoking (Howard et al. 1998). Patients with type $2 \mathrm{DM}$ are at high risk for cardiovascular disease (CVD); their risk is 2- to 6-fold higher than in subjects without diabetes (Kannel and McGee 1979, Stamler et al. 1993). Accelerated atherosclerosis in diabetic subjects is partially explained by the atherogenic risk factors associated with the metabolic syndrome (Alberti et al. 2005).

Atherosclerosis is a systemic, multifactorial disease. Nonetheless, atherosclerosis remains a geometrically focal disease, preferentially affecting the outer edges of vessel bifurcations (Fox et al. 1982). Local hemodynamic factors participate in the physiopathology of atherogenesis, accounting for the focal nature of the process (Asakura and Karino 1990). The main local hemodynamic factor is wall shear stress (WSS), the frictional force acting tangentially to the endothelial surface as a result of blood flow (Malek et al. 1999). Wall shear stress is directly related to wholeblood viscosity and to wall shear rate (WSR) (Girerd et al. 1996). WSR is defined as the difference between 
adjacent velocities in the vascular lumen. The ratio between the maximum velocity at the center of the artery and vessel radius is a common approximation of WSS (Hoeks et al. 1995). Wall shear rate can be used as an approximation of WSS (Hoeks et al. 1995, Malek et al. 1999). In the atherosclerosis-prone sites, blood flow is slow and changes its direction during the cardiac cycle, resulting in a low net hemodynamic shear stress. In contrast, vessel regions that are exposed to steady blood flow and a higher magnitude of shear stress remain comparatively plaque-free e.g. flow-dividers in bifurcation (Zarins et al. 1983, Gnasso et al. 1997). Lower WSS induces rather larger lesions with vulnerable plaque phenotype, whereas vortices with oscillatory WSS induce stable lesions (Cheng et al. 2006). Wall shear stress is not implicated only in vascular pathobiology, but also in vascular remodeling (Gibbons and Dzau 1994), and is a critical determinant of vessel caliber (Langille and O'Donnell 1986). The mechanisms, by which low WSS can cause arterial damage are known for a long time: the resultant stagnation of blood permits increased uptake of atherogenic blood particles as a result of increased residence time (Zarins et al. 1983). Wall shear stress can change the morphology and orientation of endothelial cell layer (Malek et al. 1999). Moreover, exposure of the arterial wall to a relatively low WSS may increase the vulnerability of these regions of the vessel to atherosclerosis (Malek et al. 1999). Low WSS modulates the transcription of genes for nitric oxide, and increased local production of mitogenic substances (Traub and Berk 1998). This complex endothelial cell response to shear stress may also provide a mechanism by which known risk factors act to promote atherosclerosis.

Carotid atherosclerosis is also locally influenced by WSS. Irace et al. (1999) demonstrated that subjects suffering from carotid atherosclerosis, but with low calculated cardiovascular risk have lower WSS of the common carotid artery (CCA) than controls. Investigation on patients affected by unilateral carotid atherosclerosis demonstrated that shear stress is lower in the carotid arteries with plaques than in contralateral plaque-free arteries (Gnasso et al. 1997). According to the study carried out by Irace et al. (1999) DM subjects have lower WSS of compared with age-matched healthy control subjects.

The high risk of CVD that accompanies metabolic syndrome and DM mandates comprehensive and complex preventive care. Drug therapy indicated for cardiovascular risk reduction includes insulin sensitisers (metformin), angiotensin-converting-enzyme inhibitors (ACEI) (Yusuf et al. 2000, Chitravas et al. 2007) and lipid lowering therapy (statins) (Furberg et al. 1994, Crouse et al. 1995, Amarenco and Tonkin 2004). However, despite this medication the diabetics have high risk of cardiovascular events. The aim of our study was to test the hypothesis that DM subjects with metabolic syndrome compensated by metformin, with established statin and ACEI therapy, still have lower WSR in the common carotid artery than healthy controls.

\section{Methods}

Diabetics with metabolic syndrome according NCEP ATP III criteria (Alberti et al. 2005), treated with metformin, statin and ACEI for more than 6 months were included into this study. All diabetics were overweight with central obesity (waist circumference above $102 \mathrm{~cm}$ in men and $88 \mathrm{~cm}$ in women). Diabetics were enrolled from the outpatient department, Third Department of Internal Medicine General University Hospital. We also examined healthy, age- and sex comparable subjects.

Blood pressure (BP) was measured on the right arm, after 5 min rest, in a sitting position. Serum total cholesterol, triglycerides and HDL-cholesterol levels were measured using automated analyzer methods. LDLcholesterol concentrations were calculated using the Friedewald's formula. No participants had values of triglycerides above $4 \mathrm{mmol} / \mathrm{l}$. Ultrasound examination was performed by the use of a linear-array $3-11 \mathrm{MHz}$ probe of SONOS 5500 (Philips, Andover, Massachusetts, USA). The examinations were performed in fasting state (at least $12 \mathrm{~h}$ ) during morning hours. The subjects were kept in supine position with their heads slightly extended. We scanned common carotid artery (CCA), carotid bifurcations and the origins of the internal carotid arteries in longitudinal and transverse planes. Subjects with stenosis of the carotid tree or atherosclerotic plaque were excluded. Plaque was defined as a focal structure encroaching into the arterial lumen of at least $0.5 \mathrm{~mm}$ or $50 \%$ of the surrounding intima-media thickness (IMT) value, or demonstrates a thickness $>1.5 \mathrm{~mm}$ as measured from the media-adventitia interface to the intima-lumen interface (Meijer et al. 2006). Ultrasound measurements were performed in CCA $1-2 \mathrm{~cm}$ proximal to the bifurcation. The distal segments of CCA were recorded digitally for further analysis. Blood flow velocity was 
detected with the sample volume placed in the center of CCA. Peak systolic $\left(\mathrm{V}_{\text {peak }}\right)$, end-diastolic $\left(\mathrm{V}_{\text {min }}\right)$, and mean velocities $\left(\mathrm{V}_{\text {mean }}\right)$ were recorded.

Both, the internal diameter (ID) and the common carotid intima-media thickness (CIMT) were analyzed off-line by specialized software Image Pro-Plus version 4.0 (Media Cybernetics, Silver Spring, MD, USA). The reader was the same throughout the study and was blinded with regard to the subject investigated. CIMT, defined as the distance between two parallel lines: the lumen-intima and media-adventitia boundaries, was measured on the far wall of CCA and the average of three measurements was calculated. ID, defined as the distance between the leading edge of the echo produced by the intima-lumen interface of the near arterial wall and to the leading edge of the echo produced by the lumen-intima interface of the far wall, was measured on the top of the $\mathrm{R}$-wave of QRS complex.

Wall shear rate was calculated using the Poiseuillian parabolic model of velocity distribution across the arterial lumen based on the assumption of laminar blood flow, according to the following formula (Gnasso et al. 1996, Jiang et al. 2000):

$$
\begin{aligned}
& \mathrm{WSR}_{\text {peak }}=4 \times \mathrm{VV}_{\text {peak }} / \mathrm{ID} \\
& \mathrm{WSR}_{\text {mean }}=4 \times \mathrm{V}_{\text {mean }} / \mathrm{ID},
\end{aligned}
$$

where WSR is wall shear rate $\left(\mathrm{s}^{-1}\right), \mathrm{V}$ is the velocity $\left(\mathrm{cm} . \mathrm{s}^{-1}\right)$ and ID is the arterial diameter. WSR was calculated separately for peak and mean blood flow velocity.

\section{Statistical analysis}

Because the right and left sides were analyzed separately, the analyses concerning carotid parameters were based on 52 samples in the diabetic group and 44 in the control subjects.

Statistical analysis was performed by Statistica for Windows ver.6.0 statistical software (StatSoft, In., Tulsa, OK, USA). Clinical differences between diabetics and controls were analyzed using an unpaired $t$-test. Data are expressed as mean \pm S.D.. The analysis of covariance (ANCOVA) was used to compare hemodynamic differences between age-adjusted DM subjects and controls. Univariate correlation analysis was performed to test a possible influence of age, ID, systolic blood pressure (SBP) and body mass index (BMI) on WSR and CIMT. Data are expressed as mean \pm S.D. and $\mathrm{p}<0.05$ was considered statistically significant.
Table 1. Clinical characteristics of diabetic and control subjects.

\section{Diabetes Controls p-value mellitus}

\begin{tabular}{lccc}
\hline $\begin{array}{l}\text { Age (years) } \\
\text { Body mass index } \\
\left(\mathrm{kg} / \mathrm{m}^{2}\right)\end{array}$ & $63 \pm 9$ & $60 \pm 8$ & 0.08 \\
$\begin{array}{l}\text { Diabetes mellitus } \\
\text { duration (years) }\end{array}$ & $7(1-18)$ & - & \\
$\begin{array}{l}\text { HbAlc (\%) } \\
\text { Systolic blood }\end{array}$ & $5.5 \pm 0.6$ & $3.8 \pm 0.4$ & $<0.001$ \\
$\begin{array}{l}\text { pressure (mmHg) } \\
\text { Diastolic blood }\end{array}$ & $80 \pm 8$ & $79 \pm 11$ & 0.001 \\
$\begin{array}{l}\text { pressure (mmHg) } \\
\text { Total cholesterol } \\
\text { (mmol/l) }\end{array}$ & $4.4 \pm 0.9$ & $5.1 \pm 0.8$ & $<0.001$ \\
$\begin{array}{l}\text { HDL- cholesterol } \\
\text { (mmol/l) }\end{array}$ & $1.2 \pm 0.2$ & $1.6 \pm 0.4$ & $<0.001$ \\
$\begin{array}{l}\text { LDL- cholesterol } \\
\text { (mmol/l) }\end{array}$ & $2.4 \pm 0.6$ & $2.9 \pm 0.7$ & 0.001 \\
$\begin{array}{l}\text { Triglycerides } \\
\text { (mmol/l) }\end{array}$ & $1.8 \pm 1.4$ & $1.4 \pm 0.5$ & 0.01 \\
\hline
\end{tabular}

Data are expressed as mean \pm S.D. Clinical differences between diabetics and controls were analyzed using an unpaired $t$-test.

\section{Results}

Table 1 shows clinical and biochemical characteristics of diabetics and that of controls. Diabetics had higher systolic blood pressure than healthy controls $(137 \pm 17 \mathrm{mmHg}$ vs. $125 \pm 20 \mathrm{mmHg}, \mathrm{p}<0.08)$ despite being treated with ACEI. Subjects in both groups were overweight, but body mass index was significantly higher in diabetics $(29 \pm 3$ vs. $26 \pm 3, \quad \mathrm{p}<0.001)$. The total cholesterol $(4.4 \pm 0.9 \mathrm{mmol} / 1$ vs. $5.1 \pm 0.8 \mathrm{mmol} / 1, \mathrm{p}<0.001)$ and LDL cholesterol $(2.4 \pm 0.6 \mathrm{mmol} / \mathrm{l}$ vs. $2.9 \pm 0.7 \mathrm{mmol} / \mathrm{l}$, $\mathrm{p}<0.001)$ were lower in diabetics, as a result of statin treatment. HDL cholesterol was lower in DM subjects $(1.2 \pm 0.2 \mathrm{mmol} / 1$ vs. $1.6 \pm 0.4 \mathrm{mmol} / \mathrm{l}, \mathrm{p}<0,001)$ and the triglycerides were higher $(1.8 \pm 1.4 \mathrm{mmol} / \mathrm{l}$ vs. $1.4 \pm 0.5$ $\mathrm{mmol} / \mathrm{l}, \mathrm{p}<0.01)$.

Hemodynamic parameters are listed in Table 2. Peak WSR was significantly lower in diabetics than in healthy controls $\left(410 \pm 130 \mathrm{~s}^{-1}\right.$ vs. $\left.487 \pm 111 \mathrm{~s}^{-1}, \mathrm{p}=0.003\right)$, because of both thinner lumen $(6.7 \pm 0.92 \mathrm{~mm}$ vs. $5.9 \pm$ $0.64 \mathrm{~mm}, \mathrm{p}<0.001)$ and slower blood flow velocity $(67.0$

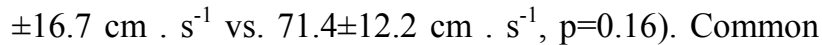
carotid intima-media thickness was significantly lower in 
Table 2. Hemodynamic parameters.

\begin{tabular}{|c|c|c|c|}
\hline & $\begin{array}{l}\text { Diabetes } \\
\text { mellitus }\end{array}$ & Controls & p - value \\
\hline Number & 52 & 44 & \\
\hline $\begin{array}{l}\text { Internal } \\
\text { diameter }(\mathrm{mm})\end{array}$ & $6.7 \pm 0.92$ & $5.9 \pm 0.64$ & $<0.001$ \\
\hline $\begin{array}{l}\text { Intima-media } \\
\text { thickness ( } \mathrm{mm})\end{array}$ & $0.73 \pm 0.12$ & $0.64 \pm 0.11$ & $<0.001$ \\
\hline $\begin{array}{l}\text { Pulse pressure } \\
\text { (mmHg) }\end{array}$ & $53.1 \pm 10.7$ & $45.7 \pm 2.0$ & 0.02 \\
\hline $\begin{array}{l}\text { Velocity peak } \\
\left(\mathrm{cm} . \mathrm{s}^{-1}\right)\end{array}$ & $67.0 \pm 16.7$ & $71.4 \pm 12.2$ & 0.16 \\
\hline $\begin{array}{l}\text { Velocity mean } \\
\left(\mathrm{cm} \cdot \mathrm{s}^{-1}\right)\end{array}$ & $33.0 \pm 8.1$ & $39.4 \pm 6.7$ & $<0.001$ \\
\hline $\begin{array}{l}W S R_{\text {peak }} \\
\left(s^{-1}\right)\end{array}$ & $410 \pm 130$ & $487 \pm 111$ & 0.003 \\
\hline $\begin{array}{l}W S R_{\text {mean }} \\
\left(s^{-1}\right)\end{array}$ & $204 \pm 71$ & $269 \pm 62$ & $<0.001$ \\
\hline
\end{tabular}

ANCOVA - Analysis of covariance, values shown as mean \pm S.D.

healthy controls $(0.73 \pm 0.12 \mathrm{~mm}$ vs. $0.64 \pm 0.11 \mathrm{~mm}$, $\mathrm{p}<0.001$ ). These results remained significant even when adjusted for systolic BP.

In diabetic group, we found significant correlations between peak wall shear rate and age $(r=-0.48, p<0.0001)$ as well as between mean wall shear rate and age $(\mathrm{r}=-0.39, \mathrm{p}=0.004)$.

\section{Discussion}

Our data demonstrate that treated diabetics with metabolic syndrome still have lower wall shear rate of the common carotid artery compared to healthy controls. These findings suggest that DM subjects with metabolic syndrome have a local carotid hemodynamic profile more prone to plaque development.

In our study, the decrease of WSR was the consequence of both lower blood flow velocity and enlargement of CCA. It was shown that the diameter of CCA increases with age (Eigenbrodt et al. 2006). Our diabetics were slightly older than healthy controls, but we believe that this difference was not so high to explain different CCA diameters. Moreover, we added the age as a confounding factor to the analysis of covariance.

Eigenbrodt et al. (2006) reported that persons with pre-existing atherosclerotic disease or atherosclerotic risk factors have larger carotid diameters than persons without such attributes. This is thought to be an adaptive phenomenon (Safar et al. 1998). Hypertension per se is a known variable associated with large internal and interadventitial diameter of CCA (Boutouyrie et al. 1999). In the present study, we found a significant correlation between ID and SBP. Our results are in agreement with previous observations of such a relationship between ID and blood pressure in treated hypertension (Chironi et al. 2003). The hypertension exerts a fatiguing effect on the elements of the arterial wall (i.e. elastin and collagen), resulting in degenerative changes and interadventitial enlargement. The role of DM in enlargement of CCA is not completely clarified. Henry et al. (2004) reported that DM is associated with a pattern of compensatory remodeling, i.e. preservation ID at increased CIMT. Diabetics in our study had dilated CCA, i.e. outward arterial remodeling (characterized by an increase of ID caused by a greater change in interadventicial diameter than in CIMT). This pattern of arterial remodeling of CCA appears maladaptive, and is associated with ischemic stroke independently of carotid atherosclerosis and cardiovascular risk factors (Bai et al. 2007).

Decreased blood flow velocity in the CCA was reported in hypertensive subjects with left ventricular hypertrophy (Jiang et al. 1998, Kohara et al. 1999). Widening of pulse pressure in stiffer arteries was proposed as the mechanism of the alteration of blood flow velocity (Kohara et al. 1999). Another possibility for explaining decreased blood flow velocity is an abnormality of cardiac function in DM subjects. Several studies demonstrated left ventricular diastolic dysfunction as a typical abnormality at early stage of DM, independent of the confounding role of myocardial ischemia, body weight, and blood pressure (Celentano et al. 1995, Di Bonito et al. 1996).

As expected, CIMT was higher in our diabetic group than in healthy controls. One of the premises of CIMT is that it reflects atherosclerosis and cardiovascular risk. Atherosclerosis is restricted primarily to the intimal layer of the vessel wall. Ultrasound imaging cannot discriminate between the intimal layer and the medial layer of the vessel wall. An increased CIMT may reflect either intimal thickening, thickening of the medial layer, or a combination of both. In the present study, we found a strong inverse correlation between WSR and CIMT in agreement with previous observations (Gnasso et al. 1996, Zarins et al. 1983). We also found a significant 
influence of SBP and glycated hemoglobin on CIMT. Our results support the hypothesis of interactions between systemic and local risk factors able to influence atherogenesis. Association between glucose tolerance and CIMT was explained by hyperglycemia (fasting glucose or $\mathrm{HbAlc}$ ) and/or insulinemia and insulin resistance (Wagenknecht et al. 2003). Insulin in physiological concentrations stimulates the proliferation of smooth muscle cells and increases lipid activity and synthesis. High levels of glucose can damage or alter the endothelial barrier, thus allowing insulin to interact with the underlying smooth muscle cells. Systolic blood pressure is known to be associated with intima-media thickening (Vaudo et al. 2000) and this finding was confirmed in our study. Linhart et al. (1996) demonstrated that carotid artery structure may be representative of LV mass even when it is within normal limits.

Although WSR is a common approximation of WSS (Gnasso et al. 1997, Irace et al. 1999, Carallo et al. 2006, Tuka et al. 2006), the use of WSR might potentially lead to some inaccuracy. First limitation is that endothelial cells sense and respond to WSS, not
WSR. Gnasso et al. (1996) measured blood viscosity in vitro by use of a cone/plane viscosimeter. It was shown that even actual measurements of viscosity must not lead to real values of shear stress (Setty et al. 2002). Some authors (Zarins et al. 1983, Paszkowiak and Dardik 2003) use an arbitrary value for blood viscosity to estimate shear stress, but the use of an arbitrary value of blood viscosity would not change the statistical significance of the results. For these reasons, we used WSR measurements only.

It can be concluded from this study that treated subjects with compensated DM still have atherogenic hemodynamic profile. These findings might help to understand fast progression of atherosclerosis in diabetic subjects despite up-to-date medication.

\section{Conflict of Interest}

There is no conflict of interest.

\section{Acknowledgements}

The study was supported by the Research Project MSM 0021620807 of Ministry of Education, Czech Republic.

\section{References}

ALBERTI KG, ZIMMET P, SHAW J, for the IDF Epidemiology Task Force Consensus Group: The metabolic syndrome-a new worldwide definition. The Lancet 366: 1059-1062, 2005.

AMARENCO P, TONKIN AM: Statins for stroke prevention: disappointment and hope. Circulation 109 (Suppl 1): III44-III49, 2004.

ASAKURA T, KARINO T: Flow patterns and spatial distribution of atherosclerotic lesions in human coronary arteries. Circ Res 66: 1045-1066, 1990.

BAI CH, CHEN JR, CHIU HC, PAN WH: Lower blood flow velocity, higher resistance index, and larger diameter of extracranial carotid arteries are associated with ischemic stroke independently of carotid atherosclerosis and cardiovascular risk factors. J Clin Ultrasound 35: 322-330, 2007.

BERENSON GS, SRINIVASAN SR, BAO W, NEWMAN WP 3rd, TRACY RE, WATTIGNEY WA: Association between multiple cardiovascular risk factors and atherosclerosis in children and young adults. The Bogalusa heart study. N Engl J Med 338: 1650-1656, 1998.

BOUTOUYRIE P, BUSSY C, LACCOLEY P, GIRERD X, LALOUX B, LAURENT S: Association between local pulse pressure, mean blood pressure, and large-artery remodeling. Circulation 100: 1387-1393, 1999.

CARALLO C, LUCCA LF, CIAMEI M, TUCCI S, DE FRANCESCHI MS: Wall shear stress is lower in the carotid artery responsible for a unilateral ischemic stroke. Atherosclerosis 185: 108-113, 2006.

CELENTANO A, VACCARO O, TAMARRO P, GALDERISI M, CRIVARO M, OLIVIERO M, IMPERATORE G, PALMIERI V, IOVINO V, RICCARDI G, DE DIVITIIS O: Early abnormalities of cardiac function in noninsulin-dependent diabetes mellitus and impaired glucose tolerance. Am J Cardiol 76: 1173-1176, 1995.

CHENG C, TEMPEL D, VAN HAPEREN R, VAN DER BAAN A, GROSVELD F, DAEMEN MJ, KRAMS R, DE CROM R: Atherosclerotic lesion size and vulnerability are determined by patterns of fluid shear stress. Circulation 113: 2744-2753, 2006.

CHIRONI G, GARIEPY J, DENARIE N, BALICE M, MEGNIEN J-L, LEVENSON J, SIMON A: Influence of hypertension on early carotid artery remodeling. Arterioscler Thromb Vasc Biol 23: 1460-1464, 2003. 
CHITRAVAS N, DEWEY HM, NICOL MB, HARDING DL, PEARCE DC, THRIFT AG: Is prestroke use of angiotensin-converting enzyme inhibitors associated with better outcome? Neurology 68: 1687-1693, 2007.

CROUSE JR 3rd, BYINGTON RP, BOND MG, ESPELAND MA, CRAVEN TE, SPRINKLE JW, MCGOVERN ME, FURBERG CD: Pravastatin, lipids, and atherosclerosis in the carotid arteries (PLAC-II). Am J Cardiol 75 : 455-459, 1995.

Di BONITO P, CUOMO S, MOIO N, SIBILIO G, SABATINI D, QUATRRIN S, CAPALDO B: Diastolic dysfunction in patients with non-insulin-dependent diabetes mellitus of short duration. Diabet Med 13: 321-324, 1996.

EIGENBRODT ML, BURSAC Z, ROSE KM, COUPER DJ, TRACY RE, EVANS GW, BRANCATI FL, MEHTA JL: Common carotid arterial interadventitial distance (diameter) as an indicator of the damaging effects of age and atherosclerosis, a cross-sectional study of the Atherosclerosis Risk in Community Cohort Limited Access Data (ARICLAD), 1987-89. Cardiovasc Ultrasound 4: 1, 2006.

FOX B, JAMES K, MORGAN B, SEED A: Distribution of fatty and fibrous plaques in young human coronary arteries. Atherosclerosis 41: 337-347, 1982.

FURBERG CD, ADAMS HP JR, APPLEGATE WB, BYINGTON RP, ESPELAND MA, HARTWELL T, HUNNIGHAKE DB, LEFKOWITZ DS, PROBSTFIELD J, RILEY WA: Effect of lovastatin on early carotid atherosclerosis and cardiovascular events. Asymptomatic Carotid Artery Progression Study (ACAPS) Research Group. Circulation 90: 1679-1687, 1994.

GIBBONS GH, DZAU VJ: The emerging concept of vascular remodeling. N Engl J Med 330: 1431-1438, 1994.

GIRERD X, LONDON G, BOUTOUYRIE P, MOURAD J-J, SAFAR M, LAURENT S: Remodeling of the radial artery in response to a chronic increase in shear stress. Hypertension 27: 799-803, 1996.

GNASSO A, CARALlO C, IRACE C, SPAGNUOLO V, DE NOVARA G, MATTIOLI PL, PUJIA A: Association between intima-media thickness and wall shear stress in common carotid arteries in healthy male subjects. Circulation 94: 3257-3262, 1996.

GNASSO A, IRACE C, CARALLO C, DE FRANCESCHI MS, MOTTI C, MATTIOLI PL, PUJIA A: In vivo association between low wall shear stress and plaque in subjects with asymmetrical carotid atherosclerosis. Stroke 28: 993-998, 1997.

HENRY RM, KOSTENSE PJ, DEKKER JM, NIJPELS G, HEINE RJ, KAMP O, BOUTER LM, STEHOUWER CD: Carotid arterial remodeling: a maladaptive phenomenon in type 2 diabetes but not in impaired glucose metabolism: the Hoorn study. Stroke 35: 671-676, 2004.

HOEKS AP, SAMIJO SK, BRANDS PJ, RENEMAN RS: Noninvasive determination of shear-rate distribution across the arterial lumen. Hypertension 26: 26-33, 1995.

HOWARD G, WAGENKNECHT LE, CAI J, COOPER L, KRAUT MA, TOOLE JF: Cigarette smoking and other risk factors for silent cerebral infarction in the general population. Stroke 29: 913-917, 1998.

IRACE C, CARALLO C, CRESCENZO A, MOTTI C, DE FRANCESCHI M, MATTIOLI P, GNASSO A: NIDDM is associated with lower wall shear stress of the common carotid artery. Diabetes 48: 193-197, 1999.

JIANG YN, KOHARA K, HIWADA K: Alteration of carotid circulation in essential hypertensive patients with left ventricular hypertrophy. J Hum Hypertens 12: 173-179, 1998.

JIANG Y, KOHARA K, HIWADA K: Association between risk factors for atherosclerosis and mechanical forces in carotid artery. Stroke 31: 2319-2324, 2000.

KANNEL WB, MCGEE DL: Diabetes and cardiovascular disease. The Framingham study. JAMA 241: 2035-2038, 1979.

KOHARA K, JIANG Y, IGASE M, HIWADA K: Effect of reflection of arterial pressure on carotid circulation in essential hypertension. Am J Hypertens 12: 1015-1020, 1999.

LANGILLE BL, O'DONNELL F: Reductions in arterial diameter produced by chronic decreases in blood flow are endothelium-dependent. Science 231: 405-407, 1986.

LINHART A, GARIEPY J, GIRAL P, LEVENSON J, SIMON A: Carotid artery and left ventricular structural relationship in asymptomatic men at risk for cardiovascular disease. Atherosclerosis 127: 103-112, 1996.

MALEK AM, ALPER SL, IZUMO S: Hemodynamic shear stress and its role in atherosclerosis. JAMA 282: 2035-2042, 1999. 
MAYER-DAVIS EJ, D'AGOSTINO R JR, KARTER AJ, HAFFNER SM, REWERS MJ, SAAD M, BERGMAN RN: Intensity and amount of physical activity in relation to insulin sensitivity: the Insulin Resistance Atherosclerosis Study. JAMA 279: 669-674, 1998.

MEIJER R, GROBEE DE, BOTS ML: Mannheim consensus on carotid intima-media thickness: opposite and complementary points of view. Cerebrovasc Dis 21: 415-416, 2006.

PASZKOWIAK JJ, DARDIK A: Arterial wall shear stress: observations from the bench to the bedside. Vasc Endovasc Surg 37: 47-57, 2003.

SAFAR ME, LONDON GM, ASMAR R, FROHLICH ED: Recent advances on large arteries in hypertension. Hypertension 32: 156-161, 1998.

SETTY SP, SALLES-CUNHA S, SCISSONS R, BEGEMAN G, FARISON J, BEEBE HG: Noninvasive measurement of shear rate in autologous and prosthetic bypass grafts. Vasc Endovasc Surg 36: 447-455, 2002.

STAMLER J, VACCARO O, NEATON JD, WENTWOTH D: Diabetes, other risk factors, and 12-yr cardiovascular mortality for men screened in the Multiple Risk Factor Intervention Trial. Diabetes Care 16: 434-444, 1993.

TRAUB O, BERK BC: Laminar shear stress: mechanisms by which endothelial cells transduce an atheroprotective force. Arterioscler Thromb Vasc Biol 18: 677-685, 1998.

TUKA V, SLAVÍKOVÁ M, SVOBODOVÁ J, MALÍK J: Diabetes and distal access location are associated with higher wall shear rate in feeding artery of PTFE grafts. Nephrol Dial Transplant 21: 2821-2824, 2006.

VAUDO G, SCHILLLACI G, EVANGELISTA F, PASQUALINI L, VERDECHIA P, MANNARINO E: Arterial wall thickening at different sites and its association with left ventricular hypertrophy in newly diagnosed essential hypertension. Am J Hypertens 13: 324-331, 2000.

WAGENKNECHT LE, ZACCARO D, ESPELAND MA, KARTER AJ, O'LEARY DH, HAFFNER SM: Diabetes and progression of carotid atherosclerosis: The Insulin Resistance Atherosclerosis Study. Arterioscler Thromb Vasc Biol 23: 1035-1041, 2003.

WATERS D, HIGGINSON L, GLADSTONE P, BOCCUZI SJ, COOK T, LESPERANCE J: Effects of cholesterol lowering on the progression of coronary atherosclerosis in women: a Canadian Coronary Atherosclerosis Intervention Trial (CCAIT) Substudy. Circulation 92: 2404-2410, 1995.

YUSUF S, SLEIGHT P, POGUE J, BOSCH J, DAVIES R, DAGENAIS G: Effects of an angiotensin-convertingenzyme inhibitor, ramipril, on cardiovascular events in high-risk patients. The Heart Outcomes Prevention Evaluation Study Investigators. N Engl J Med 342: 145-153, 2000.

ZARINS C, GIDDENS D, BHARADVAJ B, SOTTIURAI V, MABON R, GLAGOV S: Carotid bifurcation atherosclerosis. Quantitative correlation of plaque localization with flow velocity profiles and wall shear stress. Circ Res 53: 502-514, 1983. 